\title{
Interactions of Pratylenchus thornei and Fusarium oxysporum f. sp. ciceris on Chickpea
}

\author{
Pablo Castillo, María P. Mora-Rodríguez, Juan A. Navas-Cortés, and Rafael M. Jiménez-Díaz
}

Instituto de Agricultura Sostenible, Consejo Superior de Investigaciones Científicas (CSIC), Apdo. 4084, 14080 Córdoba, Spain. Accepted for publication 27 April 1998.

\begin{abstract}
Castillo, P., Mora-Rodríguez, M. P., Navas-Cortés, J. A., and JiménezDíaz, R. M. 1998. Interactions of Pratylenchus thornei and Fusarium oxysporum f. sp. ciceris on chickpea. Phytopathology 88:828-836.

Fusarium oxysporum f. sp. ciceris and the root-lesion nematode Pratylenchus thornei coinfect chickpeas in southern Spain. The influence of root infection by $P$. thornei on the reaction of Fusarium wilt-susceptible (CPS 1 and PV 61) and wilt-resistant (UC 27) chickpea cultivars to F. oxysporum f. sp. ciceris race 5 was investigated under controlled and field conditions. Severity of Fusarium wilt was not modified by coinfection of chickpeas by $P$. thornei and $F$. oxysporum f. sp. ciceris, in simultaneous or sequential inoculations with the pathogens. Root infection with five nematodes per $\mathrm{cm}^{3}$ of soil and 5,000 chlamydospores per $\mathrm{g}$ of soil of the fungus resulted in significantly higher numbers of propagules of $F$. oxysporum f. sp. ciceris with the wilt-susceptible cultivar CPS 1, but not with the wilt-resistant one.
\end{abstract}

ABSTRACT

Fusarium wilt, caused by Fusarium oxysporum Schlechtend.:Fr. f. sp. ciceris (Padwick) Matuo \& K. Sato, is a major constraint to production wherever chickpea (Cicer arietinum L.) is grown, particularly in the Mediterranean region and the Indian subcontinent $(15,30)$. Yield losses of up to $10 \%$ have been attributed to Fusarium wilt in India (37) and Spain (40) and up to $40 \%$ in Tunisia (4). F. oxysporum f. sp. ciceris can survive in soil several years by means of chlamydospores (16), which makes crop rotation unsuitable as a management strategy for Fusarium wilt of chickpea. Therefore, the most practical and economical method for controlling Fusarium wilt of chickpea worldwide is the use of resistant cultivars $(15,20,21)$. Root infection by plant-parasitic nematodes has been shown to affect host resistance to some formae speciales of $F$. oxysporum (27). Thus, the occurrence of plant-parasitic nematodes along with $F$. oxysporum f. sp. ciceris in soil used for chickpea production is of concern for the durability of Fusarium wilt-resistant chickpea cultivars (34).

The cereal and legume root-lesion nematode, Pratylenchus thornei Sher \& Allen, damages chickpea crops in the Mediterranean region, including southern Spain, and in the Indian subcontinent $(7-9,11,12,42)$. Populations of $P$. thornei in field soils range from 0.02 to 0.48 per $\mathrm{cm}^{3}$ in southern Spain (8). In addition, some root-knot nematodes infecting chickpea are known to interact with root-infecting fungi $(26,35,36)$, thus increasing crop damage.

Both $F$. oxysporum f. sp. ciceris and $P$. thornei are widely distributed throughout the major chickpea production areas of the world $(8,11,12,30)$. Thus, the possibility exists that these pathogens, when present together in chickpea fields, may interact synergistically, causing more damage and higher severity of Fusarium wilt than would result from infection with either pathogen alone.

Corresponding author: P. Castillo; E-mail address: ag1cascp@lucano.uco.es

Publication no. P-1998-0619-01R

(C) 1998 The American Phytopathological Society
However, infection with 10 nematodes per $\mathrm{cm}^{3}$ of soil significantly increased root infection by $F$. oxysporum $\mathrm{f}$. sp. ciceris in both cultivars, irrespective of fungal inoculum densities (250 to 2,000 chlamydospores per $g$ of soil). Plant growth was significantly reduced by $P$. thornei infection on wiltsusceptible and wilt-resistant chickpeas in controlled and field conditions, except when shorter periods of incubation (45 days after inoculation) were used under controlled conditions. Severity of root necrosis was greater in wilt-susceptible and wilt-resistant cultivars when nematodes were present in the root, irrespective of length of incubation time (45 to 90 days), densities of nematodes ( 5 and 10 nematodes per $\mathrm{cm}^{3}$ of soil), fungal inocula, and experimental conditions. Nematode reproduction on the wilt-susceptible cultivars, but not on the wilt-resistant one, was significantly increased by F. oxysporum f. sp. ciceris infections under controlled and field conditions.

Additional keywords: Cicer arietinum, pathogenicity, resistance.

However, to our knowledge, no information is available about the interaction between F. oxysporum f. sp. ciceris and P. thornei. The objective of this study was to determine the influence of root infections by $P$. thornei on the reaction of susceptible and resistant chickpea cultivars to $F$. oxysporum f. sp. ciceris, including effects on final nematode population densities in soil and roots and root colonization by the fungus.

\section{MATERIALS AND METHODS}

Pathogen inoculum and plant material. The most virulent race of $F$. oxysporum f. sp. ciceris (race 5) infecting chickpea in southern Spain and a population of $P$. thornei (Cañete population) representative of those found in the Spanish chickpea-growing areas were chosen for the studies $(9,19,22)$. Monoconidial isolate Foc 8012 of F. oxysporum f. sp. ciceris, representative of race 5 of the pathogen, was used in all studies. This isolate was collected from a chickpea field at Cañete de las Torres (Córdoba) in 1980 and has been used in previous studies $(20,40)$. The isolate was stored in sterile soil at $4^{\circ} \mathrm{C}$. Active cultures of the fungus were obtained by placing small aliquots of a soil culture on potato-dextrose agar (PDA) plates that were then incubated at $25^{\circ} \mathrm{C}$ with a 12 -h photoperiod of fluorescent and near-UV light at $36 \mu \mathrm{E} \mathrm{m}^{-2} \mathrm{~s}^{-1}$ for 7 days. Inoculum consisted of chlamydospores obtained as described by Alexander et al. (2). A suspension of autoclaved sandy loam soil in sterile distilled water (1 kg: 1 liter) was filtered through filter paper, and the extract was sterilized through a $0.22-\mu \mathrm{m}$ Millipore filter. The sterile soil extract collected in sterile 250-ml Erlenmeyer flasks (100 ml per flask) was infested with $1 \mathrm{~g}$ of fungal mycelial mass grown on Czapeck's medium and incubated on a rotary shaker at $120 \mathrm{rpm}$ for 7 days under the same conditions as the PDA cultures. To obtain mycelial mass, cultures were filtered aseptically through sterile filter paper and washed with sterile distilled water to remove conidia as well as traces of nutrients. The infested soil extract was incubated on a rotary shaker under the 
same conditions as above. After 2 months of incubation, cultures were examined by light microscopy to assure that they consisted mostly of chlamydospores. Chlamydospores then were collected by centrifugation and inoculum concentration was adjusted using a hemacytometer. Soil was infested by mixing $2 \mathrm{ml}$ of chlamydospore suspension with $5 \mathrm{~g}$ of sterile talcum powder and then thoroughly mixing with sterile soil at the appropriate proportion. The inoculum density of $F$. oxysporum $\mathrm{f}$. sp. ciceris race 5 in the infested soil was determined before use by dilution-plating on V8 juice-oxgall-PCNB agar (VOPA) (3).

The nematode population used in the studies was obtained from roots of chickpeas (cv. Blanco Lechoso) collected in fields at Cañete de las Torres (Córdoba). Starting from a single female, inoculum was increased several times on carrot disks that were incubated at $24^{\circ} \mathrm{C}$ each time for 6 weeks (7). Nematodes were extracted from carrot disks using a Baermann funnel, surface-disinfested with $0.02 \%$ ethoxyetil mercury chloride and $0.1 \%$ streptomycin solutions for 2 and $24 \mathrm{~h}$, respectively, and then thoroughly rinsed several times in sterile distilled water. Nematode population densities were determined from 1-ml aliquots, and then $10 \mathrm{ml}$ of suspension was placed around the radicle of pregerminated seeds at sowing. Control plants were treated similarly with sterile distilled water.

Fusarium wilt-resistant and -susceptible chickpea cultivars were chosen for the studies on the basis of their known reaction to $F$. oxysporum f. sp. ciceris race 5 (19,22; R. M. Jiménez-Díaz, unpublished data). Moderately susceptible cultivars CPS 1 and PV 61 and the resistant cultivar UC 27 (5) were used. All cultivars were susceptible to $P$. thornei $(7,8)$. Seeds of 'CPS 1' and 'UC 27' were kindly provided by H. A. van Rheenen (International Crops Research Institute for Semiarid Tropics, Hyderabad, India) and I. W. Buddenhagen (University of California, Davis), respectively. Seeds of each cultivar were surface-disinfested with $2 \% \mathrm{NaOCl}$ solution for $3 \mathrm{~min}$ and then germinated on autoclaved layers of moistened filter paper in petri plates at $25^{\circ} \mathrm{C}$ in the dark for $48 \mathrm{~h}$ ('CPS 1 ' and 'PV 61') or $72 \mathrm{~h}$ ('UC 27'). Germinated seeds, selected for uniformity (length of radicle $=1$ to $2 \mathrm{~cm}$ ), were sown into $15-\mathrm{cm}$-diameter clay pots (one per pot) containing 0.5 liters of an autoclaved potting mixture (sand/clay loam, 2:1, vol/vol).

Growth chamber studies. Three experiments were carried out under a controlled environment in a growth chamber. Cultivars CPS 1 and UC 27 were used in these studies. Growth chambers were adjusted to $24 \pm 1{ }^{\circ} \mathrm{C}, 60$ to $90 \%$ relative humidity, and a 14-h photoperiod of fluorescent light at $360.5 \pm 24.7 \mu \mathrm{E} \mathrm{m}^{-2} \mathrm{~s}^{-1}$. These environmental conditions are optimum for the development of $\mathrm{Fu}-$ sarium wilt in chickpea (19; J. A. Navas-Cortés and R. M. JiménezDíaz, unpublished data). Plants were watered daily with $100 \mathrm{ml}$ of tap water and fertilized weekly with $100 \mathrm{ml}$ of a nutrient solution (17).

In the first experiment, the effects of $F$. oxysporum f. sp. ciceris race 5 alone or in simultaneous inoculation with $P$. thornei on the development of Fusarium wilt of chickpea were investigated. Germinated seeds were sown in sterile soil or in soil infested with 5,000 chlamydospores of $F$. oxysporum f. sp. ciceris per $g$ of soil. For the joint inoculation, $10 \mathrm{ml}$ of sterile distilled water with nematode inoculum (five nematodes per $\mathrm{cm}^{3}$ of soil) were added to the soil at sowing. There were four inoculation treatments arranged in a completely randomized design and replicated 10 times, each replicate consisting of a single potted plant. The experiment ended 45 days after inoculation.

The second experiment tested the effects of several inoculum densities of $F$. oxysporum $\mathrm{f}$. sp. ciceris race 5 alone or in simultaneous inoculation with $P$. thornei. Because of high disease ratings on Fusarium wilt-susceptible cultivars in the first experiment, a series of lower inoculum densities of $F$. oxysporum f. sp. ciceris race 5 were used, and the duration of the experiment was extended to 90 days. Five inoculum densities of $F$.oxysporum f. sp. ciceris $(0,250,500,1,000$, and 2,000 chlamydospores per $g$ of soil) and two of $P$. thornei ( 0 and 10 nematodes per $\mathrm{cm}^{3}$ of soil) were included in a complete factorial design comprising 10 inoculation treatment combinations per cultivar. Inoculations were carried out as for the first experiment. Sterile distilled water $(10 \mathrm{ml})$ was added in treatments without the nematode. Treatments were arranged in a randomized complete block design and replicated five times, each replicate consisting of four pots with a single plant.

The third experiment tested the effects of several inoculum densities of $F$. oxysporum f. sp. ciceris race 5 alone or in simultaneous or sequential inoculations with $P$. thornei. Four inoculum densities of $F$. oxysporum f. sp. ciceris race $5(0,1,000,2,000$, and 5,000 chlamydospores per $\mathrm{g}$ soil), two inoculum densities of $P$. thornei ( 0 and 10 nematodes per $\mathrm{cm}^{3}$ of soil), and three inoculum timing treatments were included in a 4 by 2 by 3 factorial for a total of 24 inoculation treatments per cultivar. For each combination of fungal and nematode inoculum density, the inocula were introduced simultaneously (one treatment) or sequentially (two treatments). In the two sequential inoculation treatments, seeds were inoculated with one of the pathogens at sowing, and seedlings were grown in the absence of the other pathogen in soil for 10 days. Seedlings were then transplanted with the root ball intact into $15-\mathrm{cm}-\mathrm{di}$ ameter clay pots containing the same soil mixture that had been infested just with the fungus or the nematode as described above. The duration of the experiment was 90 days. Treatments were arranged in a completely randomized design replicated 10 times, each replicate consisting of a single potted plant.

Field study. To validate data from growth chamber studies under field conditions, an experiment was conducted in a sandy loam soil ( $\mathrm{pH} 8.5,1.4 \%$ organic matter) at the Alameda del Obispo Research Station near Córdoba, Spain (latitude $38^{\circ}$ north, longitude $5^{\circ}$ east). This field had not been sown to chickpea before. Chickpea cultivars CPS 1, PV 61, and UC 27 were used. In this experiment, plastic bags (10 cm wide by $40 \mathrm{~cm}$ long) containing 3 liters of an autoclaved soil mixture (sand/clay loam, 2:1, vol/vol) were used. The experiment was established on 27 March 1996. The bags were placed in rows $1 \mathrm{~m}$ apart. Within rows, bags were $40 \mathrm{~cm}$ apart and were buried only $30 \mathrm{~cm}$ deep. The experiment was arranged in a split-plot design within four randomized complete blocks, with cultivars as the main plot and a factorial of 4 by 2 inoculum density treatment combinations $(0,1,000,2,000$, and 5,000 chlamydospores of $F$. oxysporum $\mathrm{f}$. sp. ciceris race 5 per $\mathrm{g}$ of soil and 0 and 10 nematodes of $P$. thornei per $\mathrm{cm}^{3}$ of soil) as subplots. Nematode and fungus inocula were applied as previously described for simultaneous inoculations in growth chamber experiments. There were five replications per treatment combination; each replication was a bag with a single plant. Each cultivar was inoculated with all eight inoculum density treatment combinations. The experiment ended 70 days after inoculation.

Data collection and analysis. Severity of Fusarium wilt was assessed at 5- and 7-day intervals in growth chamber and field experiments, respectively, up to the end of the experiments. Disease severity was rated on a 0 to 4 scale according to the percentage of foliage with yellowing or necrosis $(0=0 \%, 1=1$ to $33 \%, 2=34$ to $66 \%, 3=67$ to $100 \%$, and $4=$ dead plant) (20). Incidence of foliar symptoms ( $I, 0$ or 1 ) and severity data ( $S$, rated from 0 to 4$)$, were used to calculate a disease intensity index (DII) (1) using the equation $D I I=(I \times S) / 4$. Additionally, for each treatment, the area under disease progress curve was estimated by trapezoidal integration (6) and standardized by duration time in days of the epidemic (SAUDPC).

When experiments were ended, isolations on VOPA were made from stem sections excised from second and eighth nodes of symptomless plants to determine the occurrence of vascular infections by $F$. oxysporum f. sp. ciceris race 5 . Stem sections $(1 \mathrm{~cm})$ were surface-disinfested in $0.4 \% \mathrm{NaOCl}$ for $1 \mathrm{~min}$, blotted dry on sterile filter paper, plated on VOPA, and incubated for 3 to 5 days under conditions described previously for fungal isolates. At the end of the experiment, roots were washed free of soil, weighed, and assessed for severity of root necrosis, nematode numbers in roots and soil, and nematode reproduction index ( $\mathrm{Rf}=$ final population/ 
initial population). Severity of root necrosis was assessed on a 0 to 10 scale according to the percentage of necrotic tissue visible, in which $0=0 \%, 1=1$ to $10 \%$, and $10=91$ to $100 \%$. Nematodes from $100 \mathrm{~cm}^{3}$ of soil and from 5 -g root samples were extracted by centrifugation (10) and used for estimating final nematode population densities. CFU per $\mathrm{g}$ of fresh root tissue were quantified at the end of the experiments by dilution-plating on VOPA and incubating as before for 3 to 5 days (29).

The first growth chamber experiment was repeated once. Homogeneity of variance between experimental runs, tested by Barlett's test of equal variances, allowed the data to be combined for analyses of variance. Because no symptoms developed on uninocu- lated control treatments, data obtained from those treatments were not included in the analysis of Fusarium wilt severity, to avoid use of zero in analysis of variance. All data on nematode population density were transformed into $\log _{10}(X+1)$. Orthogonal singledegree of freedom contrasts were computed to test the effect of selected experimental treatment combinations of interest (14).

\section{RESULTS}

In the first growth chamber experiment, no wilt symptoms developed in either the Fusarium-uninfested control plants or the Fusarium wilt-resistant cultivar UC 27 (Table 1). Severity of

TABLE 1. Effect of Fusarium oxysporum f. sp. ciceris race 5 and Pratylenchus thornei in simultaneous inoculation of Fusarium wilt-susceptible (CPS 1) and wiltresistant (UC 27) chickpea cultivars in the first growth chamber experiment ${ }^{\mathrm{a}}$

\begin{tabular}{|c|c|c|c|c|c|c|c|c|c|}
\hline \multirow[b]{2}{*}{ Inoculation treatment } & \multicolumn{2}{|c|}{ Inoculum density $^{\mathrm{b}}$} & \multirow[b]{2}{*}{$D I I^{\mathrm{c}}$} & \multirow[b]{2}{*}{ SAUDPC $^{\mathrm{d}}$} & \multirow[b]{2}{*}{$\mathrm{CFU} \mathrm{g}{ }^{-1}$ root $\times 10^{4}$} & \multirow{2}{*}{$\begin{array}{l}\text { Fresh root } \\
\text { weight }(\mathrm{g})\end{array}$} & \multirow{2}{*}{$\begin{array}{l}\text { Dry shoot } \\
\text { weight }(\mathrm{g})\end{array}$} & \multirow{2}{*}{$\begin{array}{c}\text { Root necrotic } \\
\text { severity }\end{array}$} & \multirow[b]{2}{*}{$\mathrm{Rf}^{\mathrm{f}}$} \\
\hline & $\mathrm{Pt}$ & Foc & & & & & & & \\
\hline \multicolumn{10}{|l|}{ Cultivar CPS 1} \\
\hline 1 & 0 & 0 & 0.00 & 0.00 & 0 & 11.5 & 2.4 & 3.8 & $\ldots{ }^{g}$ \\
\hline 2 & 0 & 5,000 & 0.83 & 0.56 & 181 & 3.7 & 2.0 & 6.5 & $\ldots$ \\
\hline 3 & 5 & 0 & 0.00 & 0.00 & 0 & 9.2 & 2.2 & 6.9 & 3.1 \\
\hline 4 & 5 & 5,000 & 0.66 & 0.45 & 582 & 5.6 & 1.7 & 6.3 & 5.8 \\
\hline \multicolumn{10}{|l|}{ Contrasts $(P)^{\mathrm{h}}$} \\
\hline 1 versus 2 & & & $\ldots$ & $\ldots$ & $\ldots$ & $<0.01$ & ns & $<0.01$ & $\ldots$ \\
\hline 1 versus 3 & & & $\ldots$ & $\ldots$ & $\ldots$ & ns & ns & $<0.01$ & $\ldots$ \\
\hline 2 versus 4 & & & ns & ns & $<0.01$ & ns & ns & ns & $\ldots$ \\
\hline 3 versus 4 & & & $\cdots$ & $\ldots$ & $\cdots$ & 0.01 & 0.01 & ns & $<0.01$ \\
\hline \multicolumn{10}{|l|}{ Cultivar UC 27} \\
\hline 1 & 0 & 0 & 0.00 & 0.00 & 0 & 18.8 & 3.4 & 0.0 & $\ldots$ \\
\hline 2 & 0 & 5,000 & 0.00 & 0.00 & 5 & 21.2 & 3.7 & 1.2 & $\ldots$ \\
\hline 3 & 5 & 0 & 0.00 & 0.00 & 0 & 17.2 & 3.4 & 2.3 & 3.2 \\
\hline 4 & 5 & 5,000 & 0.00 & 0.00 & 12 & 17.6 & 3.3 & 2.4 & 2.8 \\
\hline \multicolumn{10}{|l|}{ Contrasts $(P)^{\mathrm{h}}$} \\
\hline 1 versus 2 & & & $\ldots$ & $\ldots$ & $\ldots$ & ns & ns & $<0.01$ & $\ldots$ \\
\hline 1 versus 3 & & & $\ldots$ & $\ldots$ & $\ldots$ & ns & ns & $<0.01$ & $\ldots$ \\
\hline 2 versus 4 & & & $\ldots$ & $\ldots$ & ns & 0.04 & ns & $<0.01$ & $\ldots$ \\
\hline 3 versus 4 & & & $\ldots$ & $\ldots$ & $\ldots$ & ns & ns & ns & ns \\
\hline
\end{tabular}

a Data are the mean of two experiments with 10 replicated plants per treatment combination in each experiment.

${ }^{\mathrm{b}} \mathrm{Pt}=P$. thornei inoculum expressed as nematodes per $\mathrm{cm}^{3}$ of soil. Foc $=F$. oxysporum $\mathrm{f}$. sp. ciceris inoculum expressed as chlamydospores per g of soil.

c $D I I=$ disease intensity index, calculated at the last day of assessment 45 days after inoculation.

${ }^{\mathrm{d}} \mathrm{SAUDPC}=$ area under disease progress curve standardized by duration of the epidemic.

e Assessed on a scale of $0(0 \%$ necrotic tissue) to 10 (91 to $100 \%$ necrotic tissue $) 45$ days after inoculation. Data were transformed to log $(X+1)$ for analysis

${ }^{\mathrm{f}} \mathrm{Rf}$ (nematode reproduction factor) $=$ final nematode density per plant/initial nematode population density per plant. Data were transformed to log $(X+1)$ for analysis. $\mathrm{g} \ldots=$ not tested.

${ }^{\text {h }}$ Orthogonal contrast of inoculation treatments. Probability for the $t$ statistic of linear single-degree of freedom contrasts; ns $=$ not significant $(P>0.05)$.

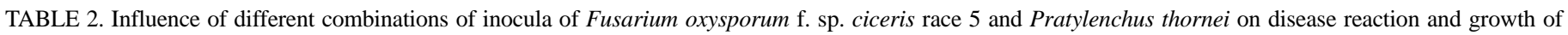
Fusarium wilt-susceptible chickpea cultivar CPS 1 with simultaneous inoculation in the second growth chamber experiment ${ }^{\mathrm{a}}$

\begin{tabular}{|c|c|c|c|c|c|c|c|c|c|}
\hline \multirow[b]{2}{*}{ Inoculation treatment } & \multicolumn{2}{|c|}{ Inoculum density ${ }^{\mathrm{b}}$} & \multirow[b]{2}{*}{$D I I^{\mathrm{c}}$} & \multirow[b]{2}{*}{ SAUDPC $^{\mathrm{d}}$} & \multirow[b]{2}{*}{$\mathrm{CFU} \mathrm{g}^{-1}$ root $\times 10^{4}$} & \multirow{2}{*}{$\begin{array}{l}\text { Fresh root } \\
\text { weight }(\mathrm{g})\end{array}$} & \multirow{2}{*}{$\begin{array}{l}\text { Dry shoot } \\
\text { weight }(\mathrm{g})\end{array}$} & \multirow{2}{*}{$\begin{array}{c}\text { Root necrotic } \\
\text { severity }\end{array}$} & \multirow[b]{2}{*}{$\mathrm{Rf}^{\mathrm{f}}$} \\
\hline & $\mathrm{Pt}$ & Foc & & & & & & & \\
\hline 1 & 0 & 0 & 0.00 & 0.00 & 0 & 15.3 & 3.4 & 5.9 & $\ldots g$ \\
\hline 2 & 0 & 250 & 0.66 & 0.52 & 77 & 8.0 & 1.9 & 6.4 & $\ldots$ \\
\hline 3 & 0 & 500 & 0.62 & 0.48 & 63 & 9.2 & 2.3 & 6.3 & $\ldots$ \\
\hline 4 & 0 & 1,000 & 0.60 & 0.46 & 93 & 9.7 & 2.5 & 6.8 & $\ldots$ \\
\hline 5 & 0 & 2,000 & 0.62 & 0.49 & 76 & 8.4 & 2.3 & 6.6 & $\ldots$ \\
\hline 6 & 10 & 0 & 0.00 & 0.00 & 0 & 10.4 & 2.7 & 6.3 & 29.6 \\
\hline 7 & 10 & 250 & 0.63 & 0.48 & 122 & 7.3 & 1.9 & 6.9 & 42.4 \\
\hline 8 & 10 & 500 & 0.63 & 0.48 & 117 & 9.1 & 2.3 & 6.7 & 46.9 \\
\hline 9 & 10 & 1,000 & 0.63 & 0.51 & 119 & 4.8 & 1.3 & 6.8 & 38.9 \\
\hline 10 & 10 & 2,000 & 0.63 & 0.46 & 138 & 5.8 & 2.0 & 7.0 & 45.4 \\
\hline \multicolumn{10}{|l|}{ Contrasts $(P)^{\mathrm{h}}$} \\
\hline 1 to 5 versus 6 to 10 & & & ns & ns & $<0.01$ & $<0.01$ & $<0.01$ & $<0.01$ & $\ldots$ \\
\hline 1 versus 2 to 5 & & & $\ldots$ & $\ldots$ & $\ldots$ & $<0.01$ & $<0.01$ & $<0.01$ & $\ldots$ \\
\hline 6 versus 7 to 10 & & & $\ldots$ & $\ldots$ & $\ldots$ & $<0.01$ & 0.01 & $<0.01$ & $<0.01$ \\
\hline
\end{tabular}

a Data are the mean of five replicates of four plants each per treatment combination.

${ }^{\mathrm{b}} \mathrm{Pt}=$ P. thornei inoculum expressed as nematodes per $\mathrm{cm}^{3}$ of soil. Foc $=F$. oxysporum $\mathrm{f}$. sp. ciceris inoculum expressed as chlamydospores per $\mathrm{g}$ of soil.

c $D I I=$ disease intensity index, calculated at the last day of assessment 90 days after inoculation.

d SAUDPC = area under disease progress curve standardized by duration time in days of the epidemic.

e Assessed on a scale of $0(0 \%$ necrotic tissue) to 10 (91 to $100 \%$ necrotic tissue $) 90$ days after inoculation. Data were transformed to log $(X+1)$ for analysis.

${ }^{\mathrm{f}} \mathrm{Rf}$ (nematode reproduction factor) $=$ final nematode density per plant/initial nematode population density per plant. Data were transformed to log $(X+1)$ for analysis. g $\ldots=$ not tested.

${ }^{\mathrm{h}}$ Orthogonal contrast of inoculation treatments. Probability for the $t$ statistic of linear single-degree of freedom contrasts; ns $=$ not significant $(P>0.05)$. 
Fusarium wilt, determined by the DII and SAUDPC, did not differ significantly for the Fusarium wilt-susceptible cultivar CPS 1, whether inoculated with $P$. thornei or not (Table 1). However, coinfection of 'CPS 1' with the fungus and the nematode significantly increased root infection by $F$. oxysporum $\mathrm{f}$. sp. ciceris race 5 as determined by the number of CFU/g of root. Inoculation with 5,000 chlamydospores of $F$. oxysporum $\mathrm{f}$. sp. ciceris race 5 per $\mathrm{g}$ of soil significantly reduced plant growth, determined by fresh root and dry shoot weights in the Fusarium wilt-susceptible, but not wiltresistant, cultivar. Inoculation with five nematodes per $\mathrm{cm}^{3}$ of soil did not affect plant growth in either cultivar, except for a reduction of root growth in the Fusarium wilt-resistant plants simultaneously inoculated with $F$. oxysporum f. sp. ciceris race 5 (Table 1 ). At the end of the experiment, infection with the fungus or the nematode gave rise to root necrosis that was significantly $(F=$ $362.3, P<0.001)$ more severe in 'CPS 1' than in 'UC 27'. Infection by $P$. thornei significantly increased root necrosis associated with fungus infection in the Fusarium wilt-resistant 'UC 27', but not in the wilt-susceptible 'CPS 1'. However, coinfection by $F$. oxysporum $\mathrm{f}$. sp. ciceris race $5 \mathrm{did}$ not increase necrosis caused by $P$. thornei alone (Table 1). Nematode reproduction was significantly higher in plants inoculated with the two pathogens compared with plants inoculated with the nematode alone in the Fusarium wilt-susceptible cultivar only (Table 1).

No wilt symptoms developed in the Fusarium-uninfested control or in the Fusarium wilt-resistant 'UC 27' plants inoculated with 250 to 2,000 chlamydospores of $F$. oxysporum f. sp. ciceris race 5 per $\mathrm{g}$ of soil in the second experiment. However, regardless of nematode treatment, a distinct yellowing affected the lowermost leaves of inoculated plants 50 days after inoculation. Infection with 10 nematodes per $\mathrm{cm}^{3}$ of soil did not significantly influence the severity of Fusarium wilt, estimated by the DII and SAUDPC, on the Fusarium wilt-susceptible cultivar CPS 1 (Table 2). However, root infection by $F$. oxysporum $\mathrm{f}$. sp. ciceris race 5 , determined by the number of CFU/g of root, was significantly higher in nematode-infected plants of both cultivars, irrespective of the inoculum density of $F$. oxysporum f. sp. ciceris race 5 (Tables 2 and 3). Contrary to the first experiment, inoculation with 10 nematodes per $\mathrm{cm}^{3}$ of soil significantly reduced fresh root and dry shoot weights of Fusarium wilt-susceptible and wilt-resistant cultivars 90 days after inoculation. Infection with less than 5,000 chlamydospores of $F$. oxysporum $\mathrm{f}$. sp. ciceris race 5 per $\mathrm{g}$ of soil reduced plant growth in Fusarium wilt-susceptible 'CPS 1', irrespective of nematode infection. However, in Fusarium wilt-resistant 'UC 27', only fresh root weight was significantly reduced and that occurred following coinfection with the two pathogens (Table 3). Plants infected by either $P$. thornei or $F$. oxysporum f. sp. ciceris race 5 showed increased root necrosis compared with controls at the end of the experiment, and root necrosis was significantly $(F=2913.3$, $P<0.001$ ) more severe in CPS 1 than in UC 27 cultivars (Tables 2 and 3 ). The severity of root necrosis was increased significantly when plants were simultaneously inoculated with the two pathogens in the Fusarium wilt-susceptible, but not in the wilt-resistant, cultivars (Tables 2 and 3). Nematode reproduction was significantly higher in the wilt-susceptible 'CPS 1' infected with $F$. oxysporum f. sp. ciceris race 5, but not in the Fusarium wilt-resistant 'UC 27' (Tables 2 and 3). Actual values of Rf were about 10-fold greater than those from the first experiment for which nematode inoculum density was half of that used in the second experiment.

When the experiment was terminated, $F$. oxysporum f. sp. ciceris race 5 was recovered from vascular tissues of 15 out of 20 symptomless 'CPS 1' plants exposed to several inoculum densities of the pathogen, but could be isolated from only 1 of 20 plants of the Fusarium wilt-resistant cultivar UC 27.

In the third growth chamber experiment, no symptoms of Fusarium wilt were found in the Fusarium-uninfested control and the inoculated Fusarium wilt-resistant 'UC 27' plants, irrespective of the inoculum densities (1,000 to 5,000 chlamydospores per $\mathrm{g}$ of soil) of $F$. oxysporum f. sp. ciceris race 5 or the time interval between inoculations (Tables 4 and 5). As in the second experiment, yellowing of basal leaves was observed in both nematode-inoculated and nematode-free plants by 50 days after inoculation. Severity of Fusarium wilt in the Fusarium wilt-susceptible cultivar CPS 1 , determined by the DII and SAUDPC, was not significantly influenced by inoculation with 10 nematodes per $\mathrm{cm}^{3}$ of soil, irrespective of $F$. oxysporum $\mathrm{f}$. sp. ciceris race 5 inoculum density and inoculation treatment (Table 4). In this cultivar, higher Fusarium wilt severity resulted from the simultaneous inoculation with $F$. oxysporum $\mathrm{f}$. sp. ciceris race 5 and $P$. thorne $i$ as compared with that in the two sequential inoculations with each of the pathogens (Table 4). Severity of Fusarium wilt was significantly higher when seedlings were inoculated with the nematode prior to that with the fungus as compared with the sequence of the fungus followed by the nematode (Table 4). As for the second growth chamber experiment, growth of 'CPS 1' plants was significantly less in both P. thornei and $F$. oxysporum f. sp. ciceris race 5-infected plants, regardless of the inoculation treatment, with one exception. When infection by $F$. oxysporum f. sp. ciceris race 5 preceded nematode infection,

TABLE 3. Influence of different combinations of inocula of Fusarium oxysporum f. sp. ciceris race 5 and Pratylenchus thornei on disease reaction and growth of Fusarium wilt-resistant chickpea cultivar UC 27 with simultaneous inoculation in the second growth chamber experiment ${ }^{\mathrm{a}}$

\begin{tabular}{|c|c|c|c|c|c|c|c|}
\hline \multirow[b]{2}{*}{ Inoculation treatment } & \multicolumn{2}{|c|}{ Inoculum density $^{\mathrm{b}}$} & \multirow[b]{2}{*}{$\mathrm{CFU} \mathrm{g}^{-1}$ root $\times 10^{4}$} & \multirow[b]{2}{*}{ Fresh root weight $(\mathrm{g})$} & \multirow[b]{2}{*}{ Dry shoot weight (g) } & \multirow[b]{2}{*}{ Root necrotic severity ${ }^{c}$} & \multirow[b]{2}{*}{$R f^{d}$} \\
\hline & $\mathrm{Pt}$ & Foc & & & & & \\
\hline 1 & 0 & 0 & 0 & 37.0 & 5.1 & 0.0 & $\ldots{ }^{\mathrm{e}}$ \\
\hline 2 & 0 & 250 & 1 & 35.5 & 5.3 & 1.1 & $\ldots$ \\
\hline 3 & 0 & 500 & 1 & 30.8 & 5.0 & 1.4 & $\ldots$ \\
\hline 4 & 0 & 1,000 & 1 & 37.3 & 5.2 & 0.9 & $\ldots$ \\
\hline 5 & 0 & 2,000 & 3 & 31.2 & 5.0 & 1.4 & $\ldots$ \\
\hline 6 & 10 & 0 & 0 & 30.8 & 4.4 & 1.9 & 31.4 \\
\hline 7 & 10 & 250 & 4 & 27.9 & 4.7 & 1.6 & 29.7 \\
\hline 8 & 10 & 500 & 3 & 21.7 & 4.6 & 1.6 & 33.0 \\
\hline 9 & 10 & 1,000 & 1 & 23.6 & 4.3 & 2.7 & 38.2 \\
\hline 10 & 10 & 2,000 & 5 & 21.1 & 4.3 & 2.6 & 31.5 \\
\hline \multicolumn{8}{|l|}{ Contrasts $(P)^{\mathrm{f}}$} \\
\hline 1 to 5 versus 6 to 10 & & & 0.01 & $<0.01$ & $<0.01$ & $<0.01$ & $\ldots$ \\
\hline 1 versus 2 to 5 & & & $\ldots$ & ns & ns & $<0.01$ & $\ldots$ \\
\hline 6 versus 7 to 10 & & & $\ldots$ & $<0.01$ & ns & ns & ns \\
\hline
\end{tabular}

a Data are the mean of five replicates of four plants each per treatment combination.

${ }^{\mathrm{b}} \mathrm{Pt}=P$. thornei inoculum expressed as nematodes per $\mathrm{cm}^{3}$ of soil. Foc $=F$. oxysporum $\mathrm{f}$. sp. ciceris inoculum expressed as chlamydospores per g of soil.

c Assessed on a scale of $0(0 \%$ necrotic tissue) to 10 (91 to $100 \%$ necrotic tissue $) 90$ days after inoculation. Data were transformed to log $(X+1)$ for analysis

${ }^{\mathrm{d}} \mathrm{Rf}$ (nematode reproduction factor) $=$ final nematode density per plant/initial nematode population density per plant. Data were transformed to log $(X+1)$ for analysis.

e $\ldots=$ not tested.

${ }^{\mathrm{f}}$ Orthogonal contrast of inoculation treatments. Probability for the $t$ statistic of linear single-degree of freedom contrasts; ns $=$ not significant $(P>0.05)$. 
shoot dry weight was comparable to that in plants infected by only $P$. thornei (Table 4). Also, plant growth was significantly higher in those plants inoculated with $F$. oxysporum f. sp. ciceris race 5 and then transplanted 10 days later to either sterile soil or soil infested with $P$. thornei compared with growth in plants inoculated first with P. thornei or simultaneously with the two pathogens (Table 4).

In the Fusarium wilt-resistant cultivar UC 27 (Table 5), nematode-infected plants had significantly lower root fresh weights when seedlings were inoculated with the fungus and the nematode simultaneously and when inoculation with the nematode preceded that with the fungus. No differences in root fresh weight were observed when seedlings were inoculated with the fungus first (Table 5). Shoot dry weight of $F$. oxysporum $\mathrm{f}$. sp. ciceris race 5-infected plants was significantly lower when seedlings were inoculated simultaneously with both pathogens (Table 5). Fresh root and dry shoot weights were significantly lower in plants simultaneously inoculated with both pathogens than in those inoculated sequentially. There were no significant differences between the two sequential inoculation treatments with respect to plant growth (Table 5).

As in the second growth chamber experiment, no necrosis developed in the roots of controls. However, the severity of root necrosis was significantly greater in plants infected with the nematode, the fungus, or both, irrespective of the inoculation treatment, at the end of the experiment. Root necrosis was significantly less severe in simultaneous as compared with sequential inoculations (Table 5). The nematode reproduction factor was of the same order of magnitude as in the second experiment. It was significantly greater in Fusarium wilt-susceptible 'CPS 1' plants inoculated with F. oxysporum f. sp. ciceris race 5 in simultaneous as well as in sequential inoculation with the fungus followed by the nematode;

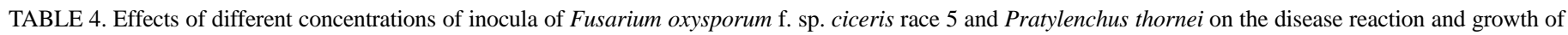
Fusarium wilt-susceptible chickpea cultivar CPS-1 in simultaneous and sequential inoculations in the third growth chamber experiment ${ }^{\mathrm{a}}$

\begin{tabular}{|c|c|c|c|c|c|c|c|c|}
\hline \multirow[b]{2}{*}{ Inoculation treatment } & \multicolumn{2}{|c|}{ Inoculum density ${ }^{\mathrm{b}}$} & \multirow[b]{2}{*}{$D I I^{\mathrm{c}}$} & \multirow[b]{2}{*}{ SAUDPC } & \multirow{2}{*}{$\begin{array}{l}\text { Fresh root } \\
\text { weight }(\mathrm{g})\end{array}$} & \multirow{2}{*}{$\begin{array}{l}\text { Dry shoot } \\
\text { weight }(\mathrm{g})\end{array}$} & \multirow{2}{*}{$\begin{array}{l}\text { Root necrotic } \\
\text { severity }\end{array}$} & \multirow[b]{2}{*}{$\mathrm{Rf}^{\mathrm{f}}$} \\
\hline & $\mathrm{Pt}$ & Foc & & & & & & \\
\hline \multicolumn{9}{|l|}{ Simultaneous inoculation } \\
\hline 1 & 0 & 0 & 0.00 & 0.00 & 15.16 & 3.09 & 4.28 & $\ldots \mathrm{g}$ \\
\hline 2 & 0 & 1,000 & 0.76 & 0.57 & 0.90 & 1.03 & 4.67 & $\ldots$ \\
\hline 3 & 0 & 2,000 & 0.66 & 0.40 & 0.82 & 1.49 & 3.89 & $\ldots$ \\
\hline 4 & 0 & 5,000 & 0.74 & 0.56 & 0.59 & 1.01 & 4.33 & $\ldots$ \\
\hline 5 & 10 & 0 & 0.00 & 0.00 & 12.44 & 1.83 & 4.72 & 30.1 \\
\hline 6 & 10 & 1,000 & 0.79 & 0.49 & 1.48 & 1.56 & 5.22 & 78.6 \\
\hline 7 & 10 & 2,000 & 0.88 & 0.61 & 0.61 & 1.27 & 4.89 & 65.8 \\
\hline 8 & 10 & 5,000 & 0.94 & 0.74 & 0.26 & 0.55 & 5.22 & 64.6 \\
\hline \multicolumn{9}{|l|}{ Contrasts $(P)^{\mathrm{h}}$} \\
\hline 1 to 4 versus 5 to 8 & & & $\ldots$ & $\ldots$ & 0.04 & $<0.01$ & $<0.01$ & $\ldots$ \\
\hline 1 versus 2 to 4 & & & $\ldots$ & $\ldots$ & $<0.01$ & $<0.01$ & ns & $\ldots$ \\
\hline 5 versus 6 to 8 & & & $\ldots$ & $\ldots$ & $<0.01$ & $<0.01$ & ns & $<0.01$ \\
\hline 2 to 4 versus 6 to 8 & & & $\mathrm{~ns}$ & ns & $\ldots$ & $\ldots$ & $\ldots$ & $\ldots$ \\
\hline \multicolumn{9}{|c|}{ Sequential inoculation 1 (nematode prior fungus) } \\
\hline 9 & 0 & 0 & 0.00 & 0.00 & 16.53 & 3.57 & 4.89 & $\ldots$ \\
\hline 10 & 0 & 1,000 & 0.51 & 0.34 & 1.67 & 1.79 & 6.22 & $\ldots$ \\
\hline 11 & 0 & 2,000 & 0.76 & 0.54 & 2.62 & 1.73 & 6.33 & $\ldots$ \\
\hline 12 & 0 & 5,000 & 0.61 & 0.38 & 1.36 & 1.42 & 6.11 & $\ldots$ \\
\hline 13 & 10 & 0 & 0.00 & 0.00 & 9.16 & 2.89 & 6.22 & $\ldots$ \\
\hline 14 & 10 & 1,000 & 0.64 & 0.43 & 0.84 & 1.45 & 6.22 & $\ldots$ \\
\hline 15 & 10 & 2,000 & 0.74 & 0.55 & 0.78 & 1.51 & 6.11 & $\ldots$ \\
\hline 16 & 10 & 5,000 & 0.84 & 0.52 & 0.91 & 1.08 & 6.33 & $\ldots$ \\
\hline \multicolumn{9}{|l|}{ Contrasts $(P)^{\mathrm{h}}$} \\
\hline 9 to 12 versus 13 to 16 & & & $\ldots$ & $\ldots$ & $<0.01$ & 0.01 & 0.04 & $\ldots$ \\
\hline 9 versus 10 to 12 & & & $\ldots$ & $\ldots$ & $<0.01$ & $<0.01$ & $<0.01$ & $\ldots$ \\
\hline 13 versus 14 to 16 & & & $\ldots$ & $\ldots$ & $<0.01$ & $<0.01$ & ns & $\ldots$ \\
\hline 10 to 12 versus 14 to 16 & & & ns & ns & $\ldots$ & $\ldots$ & $\ldots$ & $\ldots$ \\
\hline \multicolumn{9}{|c|}{ Sequential inoculation 2 (fungus prior nematode) } \\
\hline 17 & 0 & 0 & 0.00 & 0.00 & 15.92 & 3.54 & 4.44 & $\ldots$ \\
\hline 18 & 0 & 1,000 & 0.19 & 0.14 & 13.66 & 3.41 & 6.11 & $\ldots$ \\
\hline 19 & 0 & 2,000 & 0.26 & 0.21 & 14.96 & 3.51 & 6.44 & $\ldots$ \\
\hline 20 & 0 & 5,000 & 0.11 & 0.10 & 13.03 & 3.23 & 6.56 & $\ldots$ \\
\hline 21 & 10 & 0 & 0.00 & 0.00 & 12.39 & 2.96 & 5.83 & 41.2 \\
\hline 22 & 10 & 1,000 & 0.15 & 0.12 & 9.67 & 3.06 & 6.33 & 77.6 \\
\hline 23 & 10 & 2,000 & 0.15 & 0.09 & 11.02 & 3.20 & 6.56 & 66.3 \\
\hline 24 & 10 & 5,000 & 0.21 & 0.17 & 10.02 & 3.08 & 6.50 & 64.1 \\
\hline \multicolumn{9}{|l|}{ Contrasts $(P)^{\mathrm{h}}$} \\
\hline 17 to 20 versus 21 to 24 & & & $\ldots$ & $\ldots$ & 0.02 & ns & ns & $\ldots$ \\
\hline 17 versus 18 to 20 & & & $\ldots$ & $\ldots$ & ns & ns & $<0.01$ & $\ldots$ \\
\hline 21 versus 22 to 24 & & & $\ldots$ & $\ldots$ & ns & ns & 0.04 & $<0.01$ \\
\hline 18 to 20 versus 22 to 24 & & & ns & ns & $\ldots$ & $\ldots$ & $\ldots$ & $\ldots$ \\
\hline \multicolumn{9}{|c|}{ General contrasts between inoculations $(P)^{\mathrm{h}}$} \\
\hline 1 to 8 versus 9 to 24 & & & $<0.01$ & $<0.01$ & $<0.01$ & $<0.01$ & $<0.01$ & $\ldots$ \\
\hline 9 to 16 versus 17 to 24 & & & $<0.01$ & $<0.01$ & $<0.01$ & $<0.01$ & ns & $\ldots$ \\
\hline
\end{tabular}

${ }^{a}$ Data are the mean of 10 replicates, each replicate consisting of one plant per treatment combination.

${ }^{\mathrm{b}} \mathrm{Pt}=P$. thornei inoculum expressed as nematodes per $\mathrm{cm}^{3}$ of soil. Foc $=F$. oxysporum $\mathrm{f}$. sp. ciceris inoculum expressed as chlamydospores per g of soil.

c $D I I=$ disease intensity index, calculated at the last day of assessment 90 days after inoculation.

d SAUDPC $=$ area under disease progress curve standardized by duration of the epidemic.

e Assessed on a scale of 0 ( $0 \%$ necrotic tissue) to 10 (91 to $100 \%$ necrotic tissue $) 90$ days after inoculation. Data were transformed to log $(X+1)$ for analysis

${ }^{\mathrm{f}} \mathrm{Rf}$ (nematode reproduction factor) $=$ final nematode density per plant/initial nematode population density per plant. Data were transformed to log $(X+1)$ for analysis. g $\ldots=$ not tested.

${ }^{\text {h }}$ Orthogonal contrast of inoculation treatments. Probability for the $t$ statistic of linear single-degree of freedom contrasts; ns $=$ not significant $(P>0.05)$. 
but it was unaffected by $F$. oxysporum f. sp. ciceris race 5 infection in the Fusarium wilt-resistant cultivar 'UC 27' (Tables 4 and 5). Nematode reproduction could not be determined in the sequential inoculation with the nematode followed by the fungus, because the number of nematodes penetrating into roots was not estimated at transplanting (Tables 4 and 5).

No symptoms of Fusarium wilt developed in the field study in the Fusarium-uninfested control or the Fusarium wilt-resistant 'UC 27' plants inoculated with 1,000 to 5,000 chlamydospores of F. oxysporum f. sp. ciceris race 5 per $\mathrm{g}$ of soil. Inoculation with 10 nematodes per $\mathrm{cm}^{3}$ of soil did not significantly affect the severity of Fusarium wilt, as determined by the DII and SAUDPC, of either Fusarium wilt-susceptible cultivars (CPS 1 and PV 61) (Table 6). Nevertheless, nematode infection significantly reduced fresh root and dry shoot weights of Fusarium wilt-susceptible and wilt-resistant cultivars. Similarly, growth of Fusarium wilt-susceptible cultivars was significantly reduced by infection with $F$. oxysporum f. sp. ciceris race 5 either alone or together with $P$. thornei. However, infection of Fusarium wilt-resistant 'UC 27 ' by F. oxysporum f. sp. ciceris race 5 reduced fresh root weight only, and the joint infection by the fungus and the nematode did not increase damage caused by $P$. thornei alone (Table 6). Little root necrosis developed in control plants by the end of the experiment. However, infection by either pathogen alone significantly increased root necrosis in the Fusarium wilt-susceptible and, to a lesser extent, in the wilt-resistant cultivars (Table 6). Infection with $F$. oxysporum f. sp. ciceris race 5 significantly increased root necrosis caused by $P$. thornei in the two Fusarium wilt-susceptible cultivars, but not in the wilt-resistant one (Table 6). Nematode reproduction was significantly increased by infection with $F$. oxysporum f. sp. ciceris race 5 in Fusarium wilt-susceptible plants, but not in Fusarium wilt-resistant plants (Table 6). The nematode reproduced to a much lesser extent under field conditions than in controlled conditions.

\section{DISCUSSION}

This study was designed to evaluate whether or not infection of chickpea roots by $P$. thorne $i$ would influence the plant reaction to

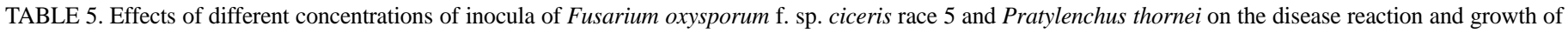
Fusarium wilt-resistant chickpea cultivar UC 27 in simultaneous and sequential inoculations in the third growth chamber experiment ${ }^{\mathrm{a}}$

\begin{tabular}{|c|c|c|c|c|c|c|}
\hline \multirow[b]{2}{*}{ Inoculation treatment } & \multicolumn{2}{|c|}{ Inoculum density ${ }^{b}$} & \multirow[b]{2}{*}{ Fresh root weight $(\mathrm{g})$} & \multirow[b]{2}{*}{ Dry shoot weight (g) } & \multirow[b]{2}{*}{ Root necrotic severity ${ }^{c}$} & \multirow[b]{2}{*}{$R f^{d}$} \\
\hline & $\mathrm{Pt}$ & Foc & & & & \\
\hline \multicolumn{7}{|l|}{ Simultaneous inoculation } \\
\hline 1 & 0 & 0 & 34.32 & 5.08 & 0.00 & $\ldots{ }^{\mathrm{e}}$ \\
\hline 2 & 0 & 1,000 & 23.41 & 4.06 & 1.78 & $\ldots$ \\
\hline 3 & 0 & 2,000 & 29.26 & 4.67 & 2.17 & $\ldots$ \\
\hline 4 & 0 & 5,000 & 23.50 & 3.86 & 2.28 & $\ldots$ \\
\hline 5 & 10 & 0 & 24.51 & 4.59 & 2.68 & 36.7 \\
\hline 6 & 10 & 1,000 & 27.28 & 4.71 & 2.68 & 34.4 \\
\hline 7 & 10 & 2,000 & 26.19 & 4.37 & 2.39 & 44.5 \\
\hline 8 & 10 & 5,000 & 18.77 & 3.46 & 2.61 & 31.0 \\
\hline \multicolumn{7}{|l|}{ Contrasts $(P)^{\mathrm{f}}$} \\
\hline 1 to 4 versus 5 to 8 & & & 0.01 & ns & $<0.01$ & $\ldots$ \\
\hline 1 versus 2 to 4 & & & $<0.01$ & $<0.01$ & $<0.01$ & $\ldots$ \\
\hline 5 versus 6 to 8 & & & ns & ns & ns & ns \\
\hline \multicolumn{7}{|c|}{ Sequential inoculation 1 (nematode prior fungus) } \\
\hline 9 & 0 & 0 & 35.99 & 5.39 & 0.00 & $\ldots$ \\
\hline 10 & 0 & 1,000 & 35.30 & 5.66 & 2.28 & $\begin{array}{l}\cdots \\
\ldots\end{array}$ \\
\hline 11 & 0 & 2,000 & 28.72 & 5.18 & 2.44 & $\ldots$ \\
\hline 12 & 0 & 5,000 & 34.31 & 5.34 & 2.28 & $\ldots$ \\
\hline 13 & 10 & 0 & 30.67 & 5.52 & 3.56 & $\ldots$ \\
\hline 14 & 10 & 1,000 & 23.94 & 5.38 & 4.33 & $\ldots$ \\
\hline 15 & 10 & 2,000 & 29.82 & 5.01 & 3.94 & $\ldots$ \\
\hline 16 & 10 & 5,000 & 27.44 & 5.43 & 2.78 & $\ldots$ \\
\hline \multicolumn{7}{|l|}{ Contrasts $(P)^{\mathrm{f}}$} \\
\hline 9 to 12 versus 13 to 16 & & & 0.01 & ns & $<0.01$ & $\ldots$ \\
\hline 9 versus 10 to 12 & & & ns & ns & $<0.01$ & $\ldots$ \\
\hline 13 versus 14 to 16 & & & ns & ns & ns & $\ldots$ \\
\hline \multicolumn{7}{|c|}{ Sequential inoculation 2 (fungus prior nematode) } \\
\hline 17 & 0 & 0 & 35.88 & 5.24 & 0.00 & $\ldots$ \\
\hline 18 & 0 & 1,000 & 35.56 & 4.67 & 2.11 & $\ldots$ \\
\hline 19 & 0 & 2,000 & 31.10 & 5.74 & 2.17 & $\ldots$ \\
\hline 20 & 0 & 5,000 & 35.50 & 5.68 & 1.94 & $\ldots$ \\
\hline 21 & 10 & 0 & 31.48 & 5.54 & 3.39 & 38.7 \\
\hline 22 & 10 & 1,000 & 33.94 & 5.52 & 3.33 & 36.6 \\
\hline 23 & 10 & 2,000 & 30.61 & 5.60 & 3.39 & 51.4 \\
\hline 24 & 10 & 5,000 & 29.58 & 5.51 & 3.28 & 32.8 \\
\hline \multicolumn{7}{|l|}{ Contrasts $(P)^{\mathrm{f}}$} \\
\hline 17 to 20 versus 21 to 24 & & & ns & ns & $<0.01$ & $\ldots$ \\
\hline 17 versus 18 to 20 & & & ns & ns & $<0.01$ & $\ldots$ \\
\hline 21 versus 22 to 24 & & & $\mathrm{~ns}$ & ns & ns & ns \\
\hline \multicolumn{7}{|c|}{ General contrasts between inoculations $(P)^{\mathrm{f}}$} \\
\hline 1 to 8 versus 9 to 24 & & & $<0.01$ & $<0.01$ & $<0.01$ & $\ldots$ \\
\hline 9 to 16 versus 17 to 24 & & & ns & ns & $<0.01$ & $\ldots$ \\
\hline
\end{tabular}

a Data are the mean of 10 replicates, each replicate consisting of one plant per treatment combination.

${ }^{\mathrm{b}} \mathrm{Pt}=P$. thornei inoculum expressed as nematodes per $\mathrm{cm}^{3}$ of soil. Foc $=F$. oxysporum $\mathrm{f}$. sp. ciceris inoculum expressed as chlamydospores per g of soil.

c Assessed on a scale of $0(0 \%$ necrotic tissue) to 10 (91 to $100 \%$ necrotic tissue) 90 days after inoculation. Data were transformed to log $(X+1)$ for analysis.

${ }^{\mathrm{d}} \mathrm{Rf}$ (nematode reproduction factor) $=$ final nematode density per plant/initial nematode population density per plant. Data were transformed to log $(X+1)$ for analysis.

e $\ldots=$ not tested.

${ }^{\mathrm{f}}$ Orthogonal contrast of inoculation treatments. Probability for the $t$ statistic of linear single-degree of freedom contrasts; ns $=$ not significant $(P>0.05)$. 
the highly virulent race 5 of $F$. oxysporum $\mathrm{f}$. sp. ciceris. Both growth chamber and field experiments clearly demonstrated that neither wilt reaction of Fusarium wilt-susceptible or wilt-resistant chickpea cultivars nor severity of Fusarium wilt in susceptible cultivars were modified by coinfection of plants with $F$. oxysporum $\mathrm{f}$. sp. ciceris race 5 and $P$. thornei. Furthermore, Fusarium wilt severity was similar whether chickpea seedlings were inoculated simultaneously or sequentially with both pathogens. That occurred irrespective of whether the plant-fungus-nematode interactions took place under continuous, optimum conditions for Fusarium wilt development in the growth chamber or under a fluctuating environment in the field. No symptoms characteristic of Fusarium wilt were found in the Fusarium wilt-resistant ' $\mathrm{UC} 27$ ' in growth chamber or field experiments. However, when 'UC 27' plants were maintained for longer than 50 days following inoculation, chlorosis of basal leaves developed. These symptoms were observed in nematode- and fungal-infected plants as well as in uninfected controls and, therefore, can be attributed to natural senescence.

Interactions between Pratylenchus spp. and several formae speciales of $F$. oxysporum have been described on several crops (28,
$31,33,38)$. These studies demonstrated that the infection by rootlesion nematodes increased the incidence or severity of Fusarium wilt on susceptible cultivars. However, those previously published results were not confirmed in other compatible plant-nematodefungus combinations (18). Thus, it appears that modification of Fusarium wilt incidence or severity may be related to the specific nematode-fungus combination. Furthermore, these controversial results indicate that interactions between soilborne fungi and rootlesion nematodes are biological and physiological rather than physical in nature (27). In our study, we used inoculum densities of $F$. oxysporum f. sp. ciceris race 5 and $P$. thornei higher than those found in soil in southern Spain (8; R. M. Jiménez-Díaz, unpublished data) or than that optimum for Fusarium wilt development (19; J. A. Navas-Cortés and R. M. Jiménez-Díaz, unpublished data) in the simultaneous and sequential inoculations of chickpeas. While none of the inoculation treatments influenced the plant reaction to the fungus, the nematode inoculum density influenced the root colonization by F. oxysporum f. sp. ciceris. Thus, root infections with five nematodes per $\mathrm{cm}^{3}$ of soil and 5,000 chlamydospores per $\mathrm{g}$ of soil resulted in a higher number of propagules of $F$. oxysporum $\mathrm{f}$.

TABLE 6. Effects of different combinations of inocula of Fusarium oxysporum f. sp. ciceris race 5 and Pratylenchus thornei on the disease reaction and growth of Fusarium wilt-susceptible (CPS 1 and PV 61) and wilt-resistant (UC 27) chickpea cultivars in simultaneous inoculation under field conditions ${ }^{\mathrm{a}}$

\begin{tabular}{|c|c|c|c|c|c|c|c|c|}
\hline \multirow[b]{2}{*}{ Inoculation treatment } & \multicolumn{2}{|c|}{ Inoculum density ${ }^{b}$} & \multirow[b]{2}{*}{$D I I^{\mathrm{c}}$} & \multirow[b]{2}{*}{ SAUDPC $^{\mathrm{d}}$} & \multirow{2}{*}{$\begin{array}{l}\text { Fresh root } \\
\text { weight }(g)\end{array}$} & \multirow{2}{*}{$\begin{array}{l}\text { Dry shoot } \\
\text { weight }(\mathrm{g})\end{array}$} & \multirow{2}{*}{$\begin{array}{c}\text { Root necrotic } \\
\text { severity }\end{array}$} & \multirow[b]{2}{*}{$\mathrm{Rf}^{\mathrm{f}}$} \\
\hline & $\mathrm{Pt}$ & Foc & & & & & & \\
\hline \multicolumn{9}{|l|}{ Cultivar CPS 1} \\
\hline 1 & 0 & 0 & 0.00 & 0.00 & 5.11 & 2.20 & 3.65 & $\ldots{ }^{\mathrm{g}}$ \\
\hline 2 & 0 & 1,000 & 0.89 & 0.57 & 1.38 & 0.65 & 7.08 & $\ldots$ \\
\hline 3 & 0 & 2,000 & 0.93 & 0.56 & 0.81 & 0.65 & 6.80 & $\ldots$ \\
\hline 4 & 0 & 5,000 & 0.98 & 0.67 & 0.55 & 0.51 & 7.05 & $\ldots$ \\
\hline 5 & 10 & 0 & 0.00 & 0.00 & 3.49 & 1.71 & 4.20 & 2.53 \\
\hline 6 & 10 & 1,000 & 0.88 & 0.56 & 0.91 & 0.55 & 7.60 & 3.57 \\
\hline 7 & 10 & 2,000 & 0.91 & 0.64 & 0.65 & 0.56 & 7.25 & 3.37 \\
\hline 8 & 10 & 5,000 & 0.94 & 0.65 & 0.38 & 0.36 & 7.38 & 2.88 \\
\hline \multicolumn{9}{|l|}{ Contrasts $(P)^{\mathrm{h}}$} \\
\hline 1 to 4 versus 5 to 8 & & & ns & ns & $<0.01$ & 0.03 & 0.01 & $\ldots$ \\
\hline 1 versus 2 to 4 & & & $\ldots$ & $\ldots$ & $<0.01$ & $<0.01$ & $<0.01$ & $\ldots$ \\
\hline 5 versus 6 to 8 & & & $\ldots$ & $\ldots$ & $<0.01$ & $<0.01$ & $<0.01$ & $<0.01$ \\
\hline \multicolumn{9}{|l|}{ Cultivar UC 27} \\
\hline 1 & 0 & 0 & 0.00 & 0.00 & 9.82 & 4.82 & 1.28 & $\ldots$ \\
\hline 2 & 0 & 1,000 & 0.00 & 0.00 & 8.53 & 3.84 & 2.55 & $\ldots$ \\
\hline 3 & 0 & 2,000 & 0.00 & 0.00 & 8.31 & 5.74 & 2.15 & $\ldots$ \\
\hline 4 & 0 & 5,000 & 0.00 & 0.00 & 8.73 & 6.14 & 2.25 & $\ldots$ \\
\hline 5 & 10 & 0 & 0.00 & 0.00 & 7.01 & 4.68 & 3.23 & 4.30 \\
\hline 6 & 10 & 1,000 & 0.00 & 0.00 & 7.14 & 4.55 & 2.63 & 5.03 \\
\hline 7 & 10 & 2,000 & 0.00 & 0.00 & 8.01 & 4.70 & 2.88 & 5.31 \\
\hline 8 & 10 & 5,000 & 0.00 & 0.00 & 6.93 & 3.75 & 2.60 & 4.41 \\
\hline \multicolumn{9}{|l|}{ Contrasts $(P)^{\mathrm{h}}$} \\
\hline 1 to 4 versus 5 to 8 & & & $\ldots$ & $\ldots$ & $<0.01$ & 0.03 & $<0.01$ & $\ldots$ \\
\hline 1 versus 2 to 4 & & & $\ldots$ & $\ldots$ & 0.02 & ns & $<0.01$ & $\ldots$ \\
\hline 5 versus 6 to 8 & & & $\cdots$ & $\cdots$ & ns & ns & ns & ns \\
\hline \multicolumn{9}{|l|}{ Cultivar PV 61} \\
\hline 1 & 0 & 0 & 0.00 & 0.00 & 12.35 & 4.01 & 1.45 & $\ldots$ \\
\hline 2 & 0 & 1,000 & 0.87 & 0.56 & 2.75 & 1.08 & 4.95 & $\ldots$ \\
\hline 3 & 0 & 2,000 & 0.93 & 0.65 & 1.48 & 0.95 & 5.90 & $\ldots$ \\
\hline 4 & 0 & 5,000 & 1.00 & 0.73 & 0.54 & 0.45 & 4.35 & $\ldots$ \\
\hline 5 & 10 & 0 & 0.00 & 0.00 & 8.45 & 2.60 & 2.60 & 2.07 \\
\hline 6 & 10 & 1,000 & 0.91 & 0.59 & 2.03 & 0.77 & 4.95 & 3.47 \\
\hline 7 & 10 & 2,000 & 0.88 & 0.57 & 2.39 & 1.28 & 5.50 & 4.15 \\
\hline 8 & 10 & 5,000 & 0.98 & 0.65 & 1.17 & 0.74 & 5.20 & 5.44 \\
\hline \multicolumn{9}{|l|}{ Contrasts $(P)^{\mathrm{h}}$} \\
\hline 1 to 4 versus 5 to 8 & & & ns & ns & 0.03 & 0.03 & $<0.01$ & $\ldots$ \\
\hline 1 versus 2 to 4 & & & $\ldots$ & $\ldots$ & $<0.01$ & $<0.01$ & $<0.01$ & $\ldots$ \\
\hline 5 versus 6 to 8 & & & $\ldots$ & $\ldots$ & $<0.01$ & $<0.01$ & $<0.01$ & $<0.01$ \\
\hline
\end{tabular}

${ }^{a}$ Data are the mean of 10 replicates, each replicate consisting of one plant per treatment combination.

${ }^{\mathrm{b}} \mathrm{Pt}=P$. thornei inoculum expressed as nematodes per $\mathrm{cm}^{3}$ of soil. Foc $=F$. oxysporum $\mathrm{f}$. sp. ciceris inoculum expressed as chlamydospores per $\mathrm{g}$ of soil.

c $D I I=$ disease intensity index, calculated at the last day of assessment 90 days after inoculation.

d SAUDPC $=$ area under disease progress curve standardized by duration of the epidemic.

e Assessed on a scale of 0 ( $0 \%$ necrotic tissue) to 10 (91 to $100 \%$ necrotic tissue) 70 days after inoculation. Data were transformed to log $(X+1)$ for analysis

${ }^{\mathrm{f}} \mathrm{Rf}$ (nematode reproduction factor) $=$ final nematode density per plant/initial nematode population density per plant. Data were transformed to log $(X+1)$ for analysis. g $\ldots=$ not tested.

${ }^{\mathrm{h}}$ Orthogonal contrast of inoculation treatments. Probability for the $t$ statistics of linear single-degree of freedom contrasts; ns $=$ not significant $(P>0.05)$. 
sp. ciceris race 5 in roots on Fusarium-susceptible cultivars, but not on the Fusarium wilt-resistant cultivar. However, infections with 10 nematodes per $\mathrm{cm}^{3}$ of soil significantly increased root infection by $F$. oxysporum f. sp. ciceris race 5 in both cultivars, irrespective of fungal inoculum densities. These results differ from observations made with other crops, for which numbers of fungal propagules were not affected by coinfection with root-lesion nematodes $(28,33)$. This suggests that $P$. thornei might modify the physiology of cortical cells of chickpea to facilitate more extensive colonization by $F$. oxysporum f. sp. ciceris race 5. Also, it appears that the nature of such modifications may be influenced by the extent of infection by the nematode as related with the nematode inoculum density.

Chickpea growth was reduced by $P$. thornei infection on both the Fusarium wilt-susceptible and wilt-resistant cultivars tested under growth chamber and field conditions. However, in growth chamber studies, reduction of plant growth was observed only when inoculated plants were incubated for a long period. This result is similar to that found in other studies $(9,12,39,42)$ and indicates that results in some of our previous studies may have been influenced by differences in the length of the observation period during experiments $(7,8)$. Similarly, reduced plant growth was observed in Fusarium wilt-susceptible plants infected with $F$. oxysporum f. sp. ciceris race 5, but that did not occur with the Fusarium wilt-resistant cultivar used, irrespective of fungal inoculum density, incubation period, or time interval between inoculations.

Infection of chickpea by $P$. thornei increased the severity of root necrosis on both the Fusarium wilt-susceptible cultivars CPS 1 and PV 61 and the wilt-resistant cultivar UC 27, irrespective of incubation period, nematode and fungal inoculum densities, and environmental conditions. These results support other researchers who found a positive correlation between severity of root necrosis and nematode population density in roots of chickpea (12). However, as some necrosis occurred in uninfected control plants, the extended necrosis in root systems of Fusarium wilt-susceptible cultivars CPS 1 and PV 61 might be related to the occurrence of phenolic compounds in the root $(25,32)$.

Reproduction of $P$. thornei was higher in roots of $F$. oxysporum f. sp. ciceris race 5-infected susceptible cultivars, but not in the resistant UC 27 cultivar, irrespective of experimental conditions, incubation period, nematode and fungal inoculum densities, or time interval between inoculations. This supports other authors who reported that reproduction of Pratylenchus spp. was stimulated in some crops by simultaneous root infections of Fusarium spp., causing cortical necrosis $(18,23,24)$ and vascular infections of Verticillium dahliae Kleb $(13,41)$. Infection of wilt-susceptible chickpea by $F$. oxysporum f. sp. ciceris race 5 may have made the root cortex of chickpea more suitable as host tissue for $P$. thornei as compared with healthy roots. That infection of the wilt-resistant cultivar by $F$. oxysporum f. sp. ciceris race 5 did not enhance the nematode reproduction might be due either to the limited extend of root infection by the fungus, the defense mechanisms involved in the resistant reaction, or both.

No modifications of the severity of Fusarium wilt was found in these experiments in spite of the enhancement of root colonization by the highly virulent race 5 of $F$. oxysporum $\mathrm{f}$. sp. ciceris in the wilt-susceptible cultivars. Thus, it appears that the durability of Fusarium wilt-resistant chickpea cultivars is unlikely to be compromised by infection with root-lesion nematodes. Nevertheless, the subsequent enhancement of nematode reproduction and fungus colonization in Fusarium wilt-susceptible chickpea is a significant observation, because of higher inoculum production of both pathogens in soil and roots, and warrants further investigations.

\section{ACKNOWLEDGMENTS}

Research was supported by grant AGF97-1479 from Comisión Interministerial de Ciencia y Tecnología (CICYT), Spain. We thank R. Rowe,
Ohio State University, and B. Hau, University of Hannover, for reviewing the manuscript prior to submission.

\section{LITERATURE CITED}

1. Acimovic, M. 1979. Evaluation procedures for the intensity of disease occurrence in sunflower. Helia 2:55-57.

2. Alexander, J. V., Bourret, J. A., Gold, A. H., and Snyder, W. C. 1966. Induction of chlamydospore formation by Fusarium solani in sterile soil extracts. Phytopathology 56:353-354.

3. Bouhot, D., and Rouxel, F. 1971. Technique sélective et quantitative d'analyse des Fusarium oxysporum et Fusarium solani dans le sol. Mode d'emploi. Ann. Phytopathol. 3:251-254.

4. Bouslama, M. 1980. Chickpea improvement in Tunisia. Pages 277-280 in: Proc. Int. Workshop Chickpea Improv. ICRISAT (Int. Crops Res. Inst. Semi-Arid Tropics), Hyderabad, India.

5. Buddenhagen, I. W., and Workneh, F. 1988. Fusarium wilt of chickpea in California. (Abstr.) Phytopathology 78:1563.

6. Campbell, C. L., and Madden, L. V. 1990. Introduction to Plant Disease Epidemiology. John Wiley \& Sons, New York.

7. Castillo, P., Gómez Barcina, A., and Jiménez-Díaz, R. M. 1996. Plantparasitic nematodes associated with chickpea in southern Spain and effects of soil temperature on reproduction of Pratylenchus thornei. Nematologica 42:211-219.

8. Castillo, P., Jiménez-Díaz, R. M., Gómez Barcina, A., and Vovlas, N. 1995. Parasitism of the root-lesion nematode Pratylenchus thornei on chickpea. Plant Pathol. 44:728-733.

9. Castillo, P., Vovlas, N., and Jiménez-Díaz, R. M. 1998. Pathogenicity and histopathology of Pratylenchus thornei populations on selected chickpea genotypes. Plant Pathol. 47:370-376.

10. Coolen, W. A. 1979. Methods for the extraction of Meloidogyne spp. and other nematodes from roots and soil. Pages 317-329 in: Root-Knot Nematodes (Meloidogyne Species) Systematics, Biology and Control. F. Lamberti and C. E. Taylor, eds. Academic Press, London.

11. Di Vito, M., Greco, N., Halila, H. M., Mabsoute, L., Labdi, M., Beniwal, S. P. S., Saxena, M. C., Singh, K. B., and Solh, M. B. 1994. Nematodes of cool-season food legumes in North Africa. Nematol. Mediterr. 22:3-10.

12. Di Vito, M., Greco, N., and Saxena, M. C. 1992. Pathogenicity of Pratylenchus thornei on chickpea in Syria. Nematol. Mediterr. 20:71-73.

13. Faulkner, L. R., and Skotland, C. B. 1965. Interaction of Verticillium dahliae and Pratylenchus minyus in Verticillium wilt of peppermint. Phytopathology 55:583-586.

14. Gomez, K. A., and Gomez, A. A. 1984. Statistical Procedures for Agricultural Research. 2nd ed. John Wiley \& Sons, New York.

15. Haware, M. P. 1990. Fusarium wilt and other important diseases of chickpea in the Mediterranean area. Options Mediterr. Ser. Semin. 9:61-64.

16. Haware, M. P., Nene, Y. L., and Natarayan, M. 1966. The survival of Fusarium oxysporum f. sp. ciceris in the soil in the absence pf chickpea. Phytopathol. Mediterr. 35:9-12.

17. Hoagland, D. R., and Arnon, D. I. 1950. The water culture method for growing plants without soil. Calif. Agric. Exp. Stn. Circ. No. 347.

18. Hutton, D. G., Wilkinson, R. E., and Mai, W. F. 1973. Effect of two plantparasitic nematodes on Fusarium dry root rot of beans. Phytopathology 63: 749-751.

19. Jiménez-Díaz, R. M., Crinó, P., Halila, M. H., Mosconi, C., and TraperoCasas, A. 1993. Screening for resistance to Fusarium wilt and Ascochyta blight in chickpea. Pages 77-96 in: Breeding for Stress Tolerance in CoolSeason Food Legumes. K. B. Singh and M. C. Saxena, eds. John Wiley \& Sons, Chichester, England.

20. Jiménez-Díaz, R. M., Singh, K. B., Trapero-Casas, A., and Trapero-Casas, J. L. 1991. Resistance in kabuli chickpeas to Fusarium wilt. Plant Dis. 75: 914-918.

21. Jiménez-Díaz, R. M., and Trapero-Casas, A. 1990. Improvement of chickpea resistance to wilt and root rot diseases. Options Mediterr. Ser. Semin. 9:65-72.

22. Jiménez-Díaz, R. M., Trapero-Casas, A., and Cabrera de la Colina, J. 1989. Races of Fusarium oxysporum f. sp. ciceris infecting chickpea in southern Spain. Pages 515-520 in: Vascular Wilt Diseases of Plants. NATO ASI Ser. H, vol. 28. E. C. Tjamos and C. H. Beckman, eds. Springer-Verlag, Berlin.

23. Jin, X., Kotcon, J. B., and Morton, J. B. 1991. Interactions between Pratylenchus penetrans and Fusarium avenaceum in red clover. Nematropica 21:105-109.

24. Jordan, E. M., Loots, G. C., Jooste, W. J., and De Waele, D. 1987. Effects of root-lesion nematodes (Pratylenchus brachyurus Godfrey and P. zeae Graham) and Fusarium moniliforme Sheldom alone or in combination, on maize. Nematologica 33:213-219.

25. Kumar, A., and Jalih, B. L. 1985. Differential effects of seed leachates on seed-borne pathogens associated with chickpea (Cicer arietinum L.). Indian Phytopathol. 38:99-103.

26. Kumar, R., Ahmad, S., and Saxena, S. K. 1988. Disease complex in chick- 
pea involving Meloidogyne javanica with Fusarium oxysporum. Int. Nematol. Network Newsl. 5:12-14.

27. Mai, W. F., and Abawi, G. S. 1987. Interaction among root-knot nematodes and Fusarium wilt fungi on host plants. Annu. Rev. Phytopathol. 25:317-338.

28. Mauza, B. E., and Webster, J. M. 1982. Suppression of alfalfa growth by concomitant populations of Pratylenchus penetrans and two Fusarium species. J. Nematol. 14:364-367.

29. Nelson, P. E., Toussoun, T. A., Burgess, L. W., Marasas, W. F. O., and Liddell, C. M. 1986. Isolating, identifying, and producing inoculum of pathogenic species of Fusarium. Pages 54-59 in: Methods for Evaluating Pesticides for Control of Plant Pathogens. K. D. Hickey, ed. The American Phytopathological Society, St. Paul, MN.

30. Nene, Y. L., and Reddy, M. V. 1987. Chickpea diseases and their control. Pages 233-270 in: The Chickpea. M. C. Saxena and K. B. Singh, eds. Commonw. Agric. Bur. Int., Wallinford, England.

31. Oyekan, P. O., and Mitchell, J. E. 1971. Effect of Pratylenchus penetrans on the resistance of a pea variety to Fusarium wilt. Plant Dis. Rep. 55: 1032-1035.

32. Sankuning, K., Thamizhseran, N., and Govindarajaln, T. 1986. Release of phenols from chickpea seeds. Int. Chickpea Newsl. 14:24-25.

33. Seinhorst, J. W., and Kuniyasu, K. 1971. Interaction on Pratylenchus penetrans and Fusarium oxysporum f. sp. pisi race 2 and Rotylenchus uniformis and F. oxysporum f. sp. pisi race 1 on peas. Nematologica 17:444-452.
34. Sharma, S. B., and Cerkauskas, R. F. 1985. Interaçao entre Meloidogyne javanica e Fusarium oxysporum f. sp. ciceris sobre o grao-de bico. Nematol. Brasil. 9:113-121.

35. Sharma, S. B., and McDonald, D. 1990. Global status of nematode problems of groundnut, pigeonpea, chickpea, sorghum and pearl millet, and suggestions for future work. Crop Prot. 9:453-458.

36. Sharma, S. B., Smith, D. H., and McDonald, D. 1992. Nematode constraints of chickpea and pigeonpea production in the semiarid tropics. Plant Dis. 76:868-874.

37. Singh, K. B., and Dahiya, B. S. 1973. Breeding for wilt resistance in chickpea. Pages 13-14 in: Symposium on Wilt Problem and Breeding for Wilt Resistance in Bengal Gram. Indian Agric. Res. Inst., New Dehli, India.

38. Sumner, D. R., and Minton, N. A. 1987. Interaction of Fusarium wilt and nematodes in Cobb soybean. Plant Dis. 71:20-23.

39. Tiyagi, S. A., and Parveen, M. 1992. Pathogenic effect of root-lesion nematode Pratylenchus thornei on plant growth, water absorption capability, and chlorophyll content of chickpea. Int. Chickpea Newsl. 26:18-20.

40. Trapero-Casas, A., and Jiménez-Díaz, R. M. 1985. Fungal wilt and root rot diseases of chickpea in southern Spain. Phytopathology 75:1146-1151.

41. Vrain, T. C. 1987. Effect of Ditylenchus dipsaci and Pratylenchus penetrans on Verticillium wilt of alfalfa. J. Nematol. 19:379-383.

42. Walia, R. K., and Seshadri, A. R. 1985. Pathogenicity of the root-lesion nematode Pratylenchus thornei on chickpea. Int. Chickpea Newsl. 12:31. 